\title{
Were there structural breaks in the effects of Japanese monetary policy? Re-evaluating policy effects of the lost decade
}

\author{
Tomoo Inoue ${ }^{a}$, Tatsuyoshi Okimoto ${ }^{\mathrm{b}, *}$ \\ ${ }^{a}$ Faculty of Economics, Seikei University, 3-3-1 Kichijoji Kitamachi, Musashino, Tokyo, Japan \\ ${ }^{\mathrm{b}}$ Faculty of Economics and IGSSS, Yokohama National University, Japan
}

Received 8 June 2007; revised 12 November 2007

Available online 29 January 2008

Inoue, Tomoo, and Okimoto, Tatsuyoshi-Were there structural breaks in the effects of Japanese monetary policy? Re-evaluating policy effects of the lost decade

This paper employs block recursive structural VAR models with Markov switching for modeling monetary policy and private sector behavior of the Japanese economy. By estimating the endogenous structural breaks, we investigate the existence, number, and nature of breaks possibly implied by the monetary policy adopted between 1975 and 2002. Results indicate that the Japanese economic system is best described by a non-absorbing two-state model, with major break happened around 1996. We also confirm that the interest rate monetary policy was effective before 1996, while monetary base shocks are identified as monetary policy shocks only after 1996. J. Japanese Int. Economies 22 (3) (2008) 320-342. Faculty of Economics, Seikei University, 3-3-1 Kichijoji Kitamachi, Musashino, Tokyo, Japan; Faculty of Economics and IGSSS, Yokohama National University, Japan.

(c) 2008 Elsevier Inc. All rights reserved.

JEL classification: E52; C11; C32

Keywords: Monetary policy; Markov switching; VAR; MCMC

\footnotetext{
* Corresponding author at: International Graduate School of Social Sciences, Yokohama National University, 79-4 Tokiwadai, Hodogaya-ku, Yokohama, Kanagawa, Japan.

E-mail addresses: inoue@econ.seikei.ac.jp (T. Inoue), okimoto@ynu.ac.jp (T. Okimoto).
} 


\section{Introduction}

After the bursting of the asset price bubble in the early 1990s, the Japanese economy experienced a long-lasting economic stagnation. The industrial production index once reached a high of 101.04 in May 1991, and sixty-eight months were needed to break this high in January $1997 .{ }^{1}$ The growth rate of real GDP from the first quarter of 1991 to the first quarter of 2002 was only $0.92 \%$ per annum, which is also very low. ${ }^{2}$ Lack of aggregate demand necessarily reduced job opportunities. As a result, the unemployment rate rose from 2.2 percent (February 1991) to 5.4 percent (February 2002). ${ }^{3}$ For these reasons, this period of turmoil is referred as the lost decade (Hayashi and Prescott, 2002) or the great recession (Kuttner and Posen, 2001).

In order to explain this economic stagnation, a number of competing hypotheses emerged from differing points of view, and have been tested empirically. These views are roughly classified into either supply-shortage hypotheses or demand-shortage hypotheses. ${ }^{4}$

As proponents of the supply-shortage hypothesis, Hayashi and Prescott (2002) emphasize the importance of the decline in the growth rate of total factor productivity (TFP). They argue that by treating TFP as an exogenous factor, the neoclassical growth model accounts well for the Japanese lost decade of growth. Concerning the effect of low TFP growth on demand-shortage, Miyao (2006) confirms the positive and persistent relationship between them by estimating a four-variable VAR model with stock prices, call rates (interbank rates), TFP, and GDP gaps. By applying historical decomposition, Miyao also finds that GDP gaps in the post-1993 period were associated with a series of negative productivity shocks. Regarding one source of low TFP growth, Caballero et al. (2006) point to the misallocation of credit by banks to unprofitable borrowers, appropriately referred to as zombie firms. In order to prevent their own bankruptcy, banks hesitated to stop extending loans to zombies. Caballero et al. argue that this reduced the potential profits from new and more productive entrants.

On the other hand, the hypotheses of demand-shortage proponents consist of three views. The first view is called a credit crunch hypothesis. This hypothesis, unlike Caballero et al. (2006), interprets a decline of the banking sector's financial intermediary function as a cause of demandshortage. The banks could not supply the necessary amount of funds to companies when needed for business investment since banks were suffering from non-performing loan problems. The second view emphasizes the misconduct of fiscal policies. Kuttner and Posen $(2001,2002)$, for example, estimate the effects of fiscal spending and tax cuts with a structural VAR, and find that a tax cut was an effective measure for stimulating the economy in the 1990s. However, the tax burden increase in 1997 was more than any of the fiscal stimulus packages that were implemented in the 1990s (Kuttner and Posen, 2001, p. 128). Therefore, they conclude that an inadequate choice of fiscal policy aggravated stagnation in the lost decade. The third view focuses on change in the effectiveness of monetary policy, a hypothesis that we investigate in this paper. Particularly in the late 1990s, when the nominal interest rate approached the zero boundary,

\footnotetext{
1 After breaking the high recorded in May 1991, the index reached a new high of 102.76 in May 1997. Immediately after this, the index dropped again due to economic stagnation. Thereafter, it required ninety-two months to revise the high again at 103.41 in January 2005 .

2 The average annual growth rate is calculated from the seasonally adjusted quarterly figures of gross domestic expenditures at constant prices (fixed, base year 1995). Data are downloaded from http://www.esri.cao.go.jp/en/sna/qe0522/gdemenuebr.html.

3 Japanese government, Statistics Bureau web page: http://www.stat.go.jp/data/roudou/longtime/03roudou.htm.

4 As a direct comparison of competing hypotheses, see Bayoumi (2001). By estimating a VAR that includes variables from each hypothesis, Bayoumi investigates their relative importance between different hypotheses.
} 
monetary policy did not seem to have any apparent positive effect on the economy (Krugman, 1998). Thus, proponents of this hypothesis argue that monetary policy lost its effect during this liquidity trap period.

In applied works, such an event is called a structural break. Although there exist several empirical works on this issue, both definition and treatment of a structural break differs among researchers. Therefore, we investigate this problem in a comprehensive manner.

The goal of this paper is to address the following four questions.

(i) Was there a structural break in the Japanese economic system in the post-1975 period?

(ii) If a structural break is suspected, did it occur once, twice, or several times?

(iii) Should we model a structural break as a permanent or temporary event?

(iv) Do those structural changes affect the effectiveness of Japanese monetary policy?

To answer these questions, this paper estimates structural VAR models with time-varying coefficients and error variances, having the time variation governed by an exogenously evolving unobserved discrete state. ${ }^{5}$ In other words, we combine traditional VAR modeling with Hamilton's (1989) Markov switching specification. By comparing the results of several Markov switching VAR models, we examine the nature of structural breaks on the effects of monetary policy in detail.

Our main findings are, first, confirmation that the Japanese economy has experienced the structural break in the post-1975 period. Second, the timing of major break is most likely in 1996, but the structural break is better described by a reversible state changes. Third, the interest rate monetary policy affects the economy in a conventional way in State 1 (which is dominant in the pre-1996 era), but its effects have significantly diminished in State 2 (which is the main state in the post-1996 period). Lastly, monetary base shocks are identified as monetary policy shocks only in State 2. Also it seems that the shocks do stimulate the economy, although they are not strong enough to generate an inflationary pressure.

The paper is organized as follows. Section 2 discusses the related literature. Section 3 presents the time-varying structural VAR model used in this paper. Section 4 explains data and discusses the empirical results, then Section 5 concludes.

\section{Brief overview of the literature}

Measuring the effects of monetary policy is not a simple task, since there is no consensus on how to measure monetary policy itself. When we use a VAR-based method for this purpose, we use it for representing the dynamics of monetary policy instruments as well as private sector behavior, i.e., the information set of the monetary authority. For example, suppose that the Bank of Japan (BoJ) uses the call rate, an overnight interest rate of the interbank call market, as a policy instrument. A portion of the realized call rate should reflect policymakers' endogenous reactions to the state of the economy, and the remainder, if any exists, is interpreted as an independent policy change. The former is called the monetary authority's "feedback rule," and the latter is called "exogenous policy shocks" (Christiano et al., 1996).

\footnotetext{
5 Empirical literature on monetary policy is roughly classified into two approaches, depending on how monetary policy is measured. One is the so-called "narrative approach" (Romer and Romer, 1989; Boschen and Mills, 1991), and the other is the "VAR-based approach." In this paper, the latter approach is used.
} 
We use a structural VAR model to describe the feedback rule as well as private sector behavior. When $n$ variables included in the system are expressed by $n \times 1$ vector $\mathbf{y}$, the structural VAR model may be expressed by ${ }^{6}$ :

$$
\mathbf{A}_{0} \mathbf{y}_{t}=\mathbf{A}_{1} \mathbf{y}_{t-1}+\mathbf{A}_{2} \mathbf{y}_{t-2}+\cdots+\mathbf{A}_{p} \mathbf{y}_{t-p}+\mathbf{u}_{t},
$$

where $p$ is the necessary lag length to describe the dynamics of the system, $\mathbf{A}_{0}$ is the $n \times n$ matrix coefficients with unit coefficients along the principal diagonal, $\mathbf{A}_{j}(j=1, \ldots, p)$ are the $n \times n$ matrix coefficients, and $\mathbf{u}_{t}$ is a structural disturbance term. Here, we assume that $\mathbf{u}_{t}$ is a Gaussian vector white noise with $E\left(\mathbf{u}_{t}\right)=\mathbf{0}$ and $E\left(\mathbf{u}_{t} \mathbf{u}_{t}^{\prime}\right)=\mathbf{D}$, where $\mathbf{D}$ is a diagonal matrix. ${ }^{7}$

Since the structural VAR model is a type of simultaneous equation, OLS estimates have a simultaneous equation bias. Therefore, for estimation purposes, we usually use a reduced form of the equation in which each endogenous regressor appears only in its lagged form. Multiplying Eq. (1) by $\mathbf{A}_{0}^{-1}$ provides VAR in reduced form as:

$$
\begin{aligned}
\mathbf{y}_{t} & =\mathbf{A}_{0}^{-1} \mathbf{A}_{1} \mathbf{y}_{t-1}+\mathbf{A}_{0}^{-1} \mathbf{A}_{2} \mathbf{y}_{t-2}+\cdots+\mathbf{A}_{0}^{-1} \mathbf{A}_{p} \mathbf{y}_{t-p}+\mathbf{A}_{0}^{-1} \mathbf{u}_{t} \\
& =\boldsymbol{\Phi}_{1} \mathbf{y}_{t-1}+\boldsymbol{\Phi}_{2} \mathbf{y}_{t-2}+\cdots+\boldsymbol{\Phi}_{p} \mathbf{y}_{t-p}+\boldsymbol{\varepsilon}_{t},
\end{aligned}
$$

where we assume that $E\left(\boldsymbol{\varepsilon}_{t} \boldsymbol{\varepsilon}_{t}^{\prime}\right)=\mathbf{A}_{0}^{-1} \mathbf{D}\left(\mathbf{A}_{0}^{-1}\right)^{\prime}=\boldsymbol{\Omega}$. Without any parameter restrictions, each equation in reduced form has the same set of regressors. This is a special form of the SUR model originally analyzed by Zellner (1962). In this case, it is well known that given initial values the equation-by-equation OLS estimates become BLUE. ${ }^{8}$ Moreover, if $\mathbf{u}_{t}$ or $\boldsymbol{\varepsilon}_{t}$ follows a multivariate normal distribution as most of papers including this paper assume, the equation-by-equation OLS estimates turn out to be the maximum likelihood estimates assuming full information.

The biggest problem of VAR-based methods is the identification of structural parameters. For example, the reduced VAR form shown in Eq. (2) contains only $n^{2} p+n(n+1) / 2$ parameters, while the structural VAR model in Eq. (1) contains $n(n-1)+n^{2} p+n$. Since a structural VAR model has an additional $n(n-1) / 2$ parameters, the structural parameters cannot be distinguished from the reduced form parameters. Therefore, it is necessary to impose at least $n(n-1) / 2$ restrictions on the structural VAR model for identification.

Given realized macroeconomic data, our task is to establish a proper structural model and provide a set of reasonable identifying assumptions in order to estimate simultaneously both the feedback rule and exogenous shocks. Hence, the evaluation of monetary policy using VARbased methods involves three issues: a choice of identifying assumptions, a choice of policy instruments, and modeling the evolution of economic status (state evolution). In the following discussion, we review these issues.

\subsection{Identification}

In the literature discussing measurement of monetary policy using VAR-based methods, the validity of identifying assumptions is often confirmed by assessing the plausibility of the estimated impulse response function to monetary policy shocks. This implies that the choice of identifying assumptions themselves is controversial. Here, we review three different approaches.

\footnotetext{
6 The constant term is omitted for notational simplicity. However, all the models that were estimated include a constant term.

7 For the more generally structured VAR model, D need not be a diagonal matrix. However, because $\mathbf{D}$ is often assumed to be a diagonal matrix, we have followed this tradition.

8 For instance, see Hayashi (2000, p. 282).
} 
The first approach is to use a recursive structural VAR, which was initiated by Sims (1980). In this approach, the variables in the system are ordered according to their degrees of exogeneity, so that matrix $\mathbf{A}_{0}$ in Eq. (1) becomes a lower triangular matrix with unit coefficients along the diagonal elements. Under this recursive structure, Cholesky decomposition can be used directly to identify the shocks. Because of this simplicity the recursive VAR model is the most widely used approach in the literature. There is, however, a drawback associated with this methodology, since it is often difficult to find such a clear-cut recursive structure in reality. Miyao $(2000,2002)$ uses this approach to examine the effects of monetary policy shocks in Japan.

The second approach imposes zero restrictions on matrix $\mathbf{A}_{0}$ in a non-recursive manner based on assumptions about short- or/and long-run economic relationships. These examples include Sims (1986), Blanchard and Quah (1989), Gali (1992), and Leeper et al. (1996). The obvious advantage of this approach is that some of the contemporaneous relationships, such as money supply and demand functions, are directly interpreted as policy-related functions, while the remainder can be expressed as a Cholesky-type block structure. The drawback of this method is, of course, that we need to identify the contemporaneous features of these policy-related functions accurately. This approach is also used in Shioji (2000) to identify the Japanese monetary policy shocks.

The third approach is a variant of the recursive approach used by Sims. Rather than imposing a fully recursive structure on matrix $\mathbf{A}_{0}$, Christiano et al. (1999) demonstrate the possibility that monetary policy shocks can be identified by using block recursive structural VAR. Christiano et al. (1999) propose to partition $\mathbf{y}_{t}$ as $\left\{\mathbf{y}_{1 t}^{\prime}, S_{t}, \mathbf{y}_{2 t}^{\prime}\right\}^{\prime}$, where $n_{1} \times 1$ vector $\mathbf{y}_{1 t}$ is a set of non-financial variables such as production and the price level, $S_{t}$ is a scalar monetary policy instrument, and $n_{2} \times 1$ vector $\mathbf{y}_{2 t}$ is a set of financial variables other than the monetary policy instrument. The model assumes that

(i) there is no instantaneous feedback to non-financial variables from monetary policy shocks, and

(ii) the monetary authority cannot observe the instantaneous value of $\mathbf{y}_{2 t}$ at the time of making policy.

With these relatively weak assumptions, matrix $\mathbf{A}_{0}$ can be partitioned into the following lower triangular block form:

$$
\mathbf{A}_{0}=\left[\begin{array}{ccc}
\mathbf{B}_{11} & \mathbf{0} & \mathbf{0} \\
\left(n_{1} \times n_{1}\right) & \left(n_{1} \times 1\right) & \left(n_{1} \times n_{2}\right) \\
\mathbf{B}_{21} & 1 & \mathbf{0} \\
\left(1 \times n_{1}\right) & & \left(1 \times n_{2}\right) \\
\mathbf{B}_{31} & \mathbf{B}_{32} & \mathbf{B}_{33} \\
\left(n_{2} \times n_{1}\right) & \left(n_{2} \times 1\right) & \left(n_{2} \times n_{2}\right)
\end{array}\right]
$$

Christiano et al. (1999) demonstrate that the impulse response function of each variable to a shock in monetary policy does not depend on the structure of $\mathbf{B}_{11}$ and $\mathbf{B}_{33}$. Thus, if we are only interested in the identification of the monetary policy shock and the evaluation of its effect by the impulse response function, it does not matter how $\mathbf{B}_{11}$ and $\mathbf{B}_{33}$ are identified. We, therefore, can use the simplest recursive identification for $\mathbf{B}_{11}$ and $\mathbf{B}_{33}$. Under this identification a model with a scalar monetary policy instrument becomes essentially a recursive structural VAR. Nonetheless necessary assumptions for the Christiano et al. identification are much weaker compared to the ones imposed on the usual recursive VAR model. 
One drawback of the Christiano et al. method is that the impulse responses to non-monetary policy shocks cannot be identified. However, this is not a problem for our purposes, since we are solely interested in identifying monetary policy shocks. In addition, this method also allows us to include multiple monetary policy instruments. To identify multiple monetary policy shocks, Keating (1996) shows that a recursive structure is required only between monetary policy instruments.

Overall, compared with the other two approaches, the identification method used by Christiano et al. (1999) imposes weaker assumptions and provides a great amount of flexibility. Therefore, in this paper, we use the Christiano et al. identification approach to evaluate the effects of Japanese monetary policy.

\subsection{Choice of monetary policy instruments}

The next issue is concerned with the choice of monetary policy instruments. This issue is also controversial. When Miyao (2002) applies recursive structural VAR to examine the effects of Japanese monetary policy for the period from January 1975 to April 1998, he attempts to search for the best indicator of the BoJ stance regarding monetary policy. Based on institutional characteristics of the operating procedures employed by the BoJ, Miyao concludes that the call market rate can be regarded as the best indicator of Japanese monetary policy, and that the interest rate is predetermined for monetary aggregates. On the other hand, by applying a non-recursive structural VAR model to Japanese data for the period from February 1977 to May 1995, Shioji (2000) identifies shocks that relate to monetary base as the monetary policy shocks.

The discussion thus far has assumed that the BoJ has only one monetary policy instrument. Identification assumptions used by Miyao (2002) and Shioji (2000) assume a scalar monetary policy instrument. In other words, this assumes that the monetary policy indicator is specified using a single monetary variable. Nevertheless, how can we specify the monetary policy indicator if it involves multiple monetary variables? The approach proposed by Bernanke and Mihov (1998) allows the specification of such a monetary policy indicator. Although a variant of recursive structural VAR, it has a unique advantage. By formulating an equilibrium model of the reserve market, this approach allows us to test hypotheses about the operating procedures of the monetary authority.

As the first application of Bernanke and Mihov's approach to Japanese data, Kasa and Popper (1997) find that lending restrictions (which are referred to as "moral suasion," or "window guidance") were an important monetary policy instrument until the first half of the 1980s, and that the call rate had become an important policy tool since the second half of the 1980s. However, their work has been criticized for not taking institutional differences between the US and Japan into account in their analysis (Shioji, 2000; Nakashima, 2006).

Recently, Nakashima (2006) applies Bernanke and Mihov's approach to Japanese data, and reexamines the importance of lending restrictions. Using data from January 1975 to June 1995, Nakashima estimates two models of the reserve market; he concludes that the BoJ targeted only the call rate, and that the call rate was the best policy indicator during the sample period.

From the discussion above, it seems reasonable to conclude that the call rate is the preferred indicator of Japanese monetary policy. However, once the call rate has approached the zero boundary in 1995, the BoJ has begun to announce that its decision to supply enough amount of reserves. Moreover, from March 2001, the BoJ has executed a new monetary policy rule called the "quantitative easing policy" under which the BoJ's policy target shifts from the level 
of call rate to the BoJ checking account balance. ${ }^{9}$ Therefore, we include monetary base as the secondary indicator of monetary policy. Hence, $S$ is a vector, not a scalar. For an identification of monetary policy shocks in this setting, we only need a recursive structure between monetary policy instruments as shown in Keating (1996). Concerning the relationship between the call rate and monetary aggregates, following the discussion by Miyao (2002), we assume that the call rate is predetermined for monetary aggregates.

\subsection{State evolution}

If VAR coefficients shift during the sample period, it implies that the propagation mechanisms of monetary policies also change. Recently, this issue is receiving greater attention.

In the study of US monetary policy, many researchers have investigated policy shifts during the Volcker era, specifically, the period from latter 1979 to 1982. Using the structural VAR model of the reserve market for the period from 1965 to 1996, Bernanke and Mihov (1998) detect two change points of coefficients, in October 1979 and October 1982. Hence, they conclude that the Fed targeted non-borrowed reserves during the 1979-1982 period, and an interest rate outside of the 1979-1982 window. On the other hand, Sims and Zha (2006) consider the structural change in both coefficients and variances of structural innovations. Surprisingly, their best model has only one state of coefficients but nine variance states during the period between January 1959 and March 2003. Thus, Sims and Zha emphasize the importance of variances rather than changes in coefficients. Their next best model allows the strength of monetary policy responses to vary with the regime, while other parameters remain fixed, except for disturbance variances. They find that the model fits best with four states, with the three main regimes correspond roughly to periods when most observers believe that monetary policy actually differed.

Both Bernanke and Mihov (1998), and Sims and Zha (2006), have modeled state evolution in discrete breaks by applying Hamilton's (1989) Markov regime switching model. Primiceri (2005), however, has modeled a time-varying structural VAR, in which the time variations of coefficients and variance of innovations are modeled as smooth and continuous changes. He argues that the aggregate behavior of the private sector in response to policy changes by the monetary authority should favor a model with smooth changes over a model with discrete breaks.

In Japan, we also have an interest in the status of the evolution of monetary policy effects, but in a different context. Many authors have argued that the effect of monetary policy was weakened during the 1990s. For example, by estimating recursive VAR models for the period from January 1975 to April 1998, Miyao (2000) has examined the emergence of structural change during the 1990s in two ways. First, he displays impulse response functions of industrial production to interest rate shocks for a pre-1993 subsample and for a post-1990 subsample, and concludes that monetary policy becomes less effective in the post-1990 period. Second, he tests the stability of VAR coefficients with the $\chi^{2}$ statistic used in Sims (1980). By grid searching for the break point, Miyao has detected a shift in VAR coefficients between 1995 and 1996. Note, however, that his test results should be interpreted with great care. This is because that the total size of his tests is much larger than $5 \%$, since he conducts $\chi^{2}$ tests with size $5 \%$ more than 20 times. $^{10}$

Fujiwara (2006), on the other hand, employs an identified Markov switching VAR (MSVAR). Assuming that there are non-absorbing two-states in Japanese economy, he estimates fivevariable MSVAR using the monthly data of industrial production, CPI, commodity prices, call

9 For theoretical implication of quantitative easing policy, see Orphanides and Wieland (2000) and McCallum (2000).

10 For example, if we conduct independent $5 \%$ tests 20 times, the total size of the tests would be $100\left(1-0.95^{20}\right) \approx 64 \%$. 
rate, and M2+CD for the period from January 1985 to December 2003. Smoothed regime probabilities suggest that

(i) the pre-1995 regime differs from the post-1999 regime, and

(ii) the period between 1995 and 1999 are transition periods.

Thus, he concludes a possibility of a structural break in the late 1990s. However, his conclusion is not strong, because he fails to examine the possibility of no structural change or the second structural change, which are points being addressed in this paper.

Although neither Miyao (2000) nor Fujiwara (2006) provides clear evidence, it is worth noting that the results obtained by these studies seem similar in several aspects. First, both suggest a possible structural break in the late 1990s. Second, the impulse response of real output to the call rate demonstrates similar patterns. Both authors find that a positive shock to the call rate lowers real output in the first regime, but this effect disappeared in the second regime. Thus, these findings provide some evidence that the effectiveness of monetary policy was weakened in the late 1990s.

We should also emphasize that their philosophies with regard to structural breaks are distinctively different. In the past, when the emergence of a structural break was an issue of empirical study, the state evolution process is treated exogenously as Miyao postulate, typically by including dummy variables or using subsample analysis. However, in recent literature, the stochastic nature of structural breaks is often emphasized. As Sims and Zha (2006) note:

It is time to abandon the idea that policy change is best modeled as a once-and-for-all, nonstochastic regime switch. Policy changes, if they have occurred, have not been monotonic, and they have been difficult to detect. Both the rational public in our models and econometricians must treat the changes in policy probabilistically, with a model of how and when the policy shifts occur and with recognition of the uncertainty about their nature and timing. (Sims and Zha, 2006, p. 56)

In this paper, following the spirit of Fujiwara (2006) and Sims and Zha (2006), we treat state evolution as a stochastic event. State evolution is modeled in the Markov switching model, and we allow both the coefficients and innovation variances to be regime dependent.

The goal of this paper is to examine state evolution in monetary policy using four aspects. First, we examine if discrete breaks actually existed in the period from January 1975 to December 2002. Needless to say, parsimonious modeling is always preferred. Hence, it is important to confirm if modeling of state evolution is indeed necessary.

Given the confirmation of structural breaks, as a second question, we examine the optimal number of break points. For instance, Miyao (2000) specifies state evolution as a once-and-for-all type change. In a Markov switching framework, Miyao's model is represented by an absorbing two-state model, i.e. a two-state model with the absorbing second state. During our sampling period, however, such significant events as financial deregulation in the late 1970s, sharp appreciation of the yen in the mid-1980s, and asset price bubbles in the late 1980s were observed. These events are very likely to affect private sector behavior as well as conduct of monetary policy. Therefore, it is safer to assume that breaks have emerged more than twice. In this paper, we set the maximum number of states to be three, and search for the optimal number of states by comparing several two-state and three-state models. 
Third, we examine the nature of state evolution. Here, we investigate whether absorbing-state models such as Miyao's (2000), or non-absorbing-state models such as Fujiwara's (2006), are preferable. Lastly, given a confirmation of structural breaks, we examine if the effectiveness of monetary policies is different across states.

Through these systematic model comparisons, we seek for a parsimoniously appropriate model that best characterizes monetary policy rules as well as private sector behavior to provide stronger and clearer conclusions regarding the presence of structural breaks in the effects of Japanese monetary policy.

\section{Model}

\subsection{Model with endogenous state evolution}

This section introduces time-varying structural VAR with time-varying coefficients and a time-varying innovation variance-covariance matrix, with time variation governed by an exogenously evolving unobserved discrete state. With a discrete regime-switching specification, the reduced-form VAR model of Eq. (2) is expressed as:

$$
\mathbf{y}_{t}=\boldsymbol{\Phi}_{1}\left(s_{t}\right) \mathbf{y}_{t-1}+\boldsymbol{\Phi}_{2}\left(s_{t}\right) \mathbf{y}_{t-2}+\cdots+\boldsymbol{\Phi}_{p}\left(s_{t}\right) \mathbf{y}_{t-p}+\boldsymbol{\varepsilon}_{t}
$$

where $s_{t}$ is a latent variable that takes a value from among $1,2, \ldots, K$, with $K$ being the number of states (or equivalently, "regimes"). Moreover, $E\left(\boldsymbol{\varepsilon}_{t} \boldsymbol{\varepsilon}_{t}^{\prime}\right)=\boldsymbol{\Omega}\left(s_{t}\right)$ is also assumed to be a function of $s_{t}$. In other words, this model allows us to specify different VAR models for different states. For the stochastic process of $s_{t}$, Hamilton (1989) proposes to model it by employing the Markov chain.

The Markov chain is a simple model that describes the dynamics of a discrete random variable. The law of state evolution is governed by the transition probability matrix $\mathbf{P}$, where the $(i, j)$ element of $\mathbf{P}$ indicates $\operatorname{Pr}\left[s_{t}=i \mid s_{t-1}=j\right]$. The expected duration of each regime and inferences about $s_{t}$ are both calculated using this matrix.

Although the model has a simple structure, it can describe various types of state evolution by imposing restrictions on the elements of matrix $\mathbf{P}$. An example below is a transition matrix of an absorbing three-state model:

$$
\mathbf{P}=\left(\begin{array}{ccc}
p_{11} & 0 & 0 \\
1-p_{11} & p_{22} & 0 \\
0 & 1-p_{22} & 1
\end{array}\right)
$$

Since the $(1,2)$ element of this transition matrix is zero, once a state moves from State 1 to State 2, it will never return to State 1. The same is true for transitions moving from State 2 to State 3. Finally, once the model reaches State 3, it will continue in State 3 for the remainder of the sample period. Also, the zero restriction on the $(3,1)$ element prevents a state change from State 1 to State 3. Therefore, by imposing restrictions on $\mathbf{P}$ in this manner, we can model two permanent structural changes within the sample period.

In this paper, we estimate four structural VAR models with different assumptions of state evolution; specifically: a model with no structural break (Model 1), an absorbing two-state model or a model with one permanent structural break (Model 2), an absorbing three-state model or a 
model with two permanent structural breaks (Model 3), and a non-absorbing two-state model (Model 4). ${ }^{11}$

Model 1 is the conventional specification in the literature. It assumes no shift in VAR parameters. Thus this is a benchmark model for other specifications. The inference based on Model 1 is appropriate if the structure among the economic variables hold constant during the sample period. This assumption, however, seems not to be realistic since the economic environment surrounding the monetary policy has changed drastically in the 1980 s and the 1990s. Therefore, we introduce three MSVAR models.

Model 2 is the simplest model that includes a structural break. This is a two-state MSVAR model with a zero restriction on the $(1,2)$ element of a $2 \times 2$ transition probability matrix $\mathbf{P}$. In other words, we impose State 2 to be an absorbing state. Due to this restriction, once a state moves from State 1 to State 2, it will never return to State 1. Since VAR coefficients in State 1 and State 2 are different, the propagation mechanisms of monetary policies could also be different between states.

As variants of Model 2, we consider two models that differ in the nature of structural breaks. Model 3 is a three-state MSVAR model with the matrix $\mathbf{P}$ defined by Eq. (3). Similar to Model 2, Model 3 premises the structural break to be a permanent event; however, the two models differ by the number of permanent break points in the sample period. In particular, we add one more permanent break point in Model 3. Under this setting, we assume that the sample period is divided into three subperiods. We now have three different propagation mechanisms of monetary policies corresponding to the three subperiods. On the other hand, it is also possible to regard the structural break as a reversible phenomenon. For example, Model 4 is a two-state MSVAR without zero restriction on the matrix $\mathbf{P}$. This is a variant of Model 2, but without the absorbing condition. Under this setting, the state of the economy can change between States 1 and 2 following a Markov chain without any restriction.

By comparing these four models, we will seek answers to the questions stated above. In so doing, we may verify the effects of structural breaks on Japanese monetary policy in the post1975 period.

Lastly, we summarize the advantages of using Markov switching for modeling structural change, rather than the dummy variable approach or the subsample analysis employed by Miyao (2000) and Kasa and Popper (1997).

The first advantage is that the timing of a structural break is endogenous. For both the dummy variable approach and subsample analysis, it is necessary to provide the timing of a structural break exogenously. However, this is a difficult task. In addition, incorrectly specifying the timing may lead to an erroneous conclusion. These problems can be avoided by endogenously establishing the timing of structural breaks using the Markov switching model.

The second advantage is the ability to evaluate the probability of each observation at a given time that is associated with a dominant state. Since structural change is endogenous in the Markov switching model, we cannot specify the point of a structural break from the estimation results. However, the smoothed probability that data at any given time are associated with each respective state is evaluated from the estimated model and the observed data. Therefore, we can evaluate the point of a structural break from this smoothed probability. Of course, both the dummy variable approach and subsample analysis can identify the point of a structural break by

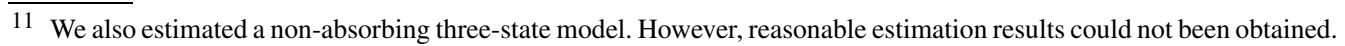


moving the break point. However, it is difficult to evaluate the probability of occurrence using these methods.

The third advantage is the ability to model not only a permanent change but also a reversible change. In fact, as many economists agree, it is highly likely that the Japanese economy experienced significant structural change after the collapse of the bubble economy, and this is what caused the lost decade. However, it is not certain whether this structural change is a permanent change, or should be considered as a temporary period of disturbance after the bubble economy collapsed. By estimating regime-switching models with both absorbing states and non-absorbing states we can assess which interpretation is more appropriate.

\subsection{Bayesian estimation via the Gibbs sampler}

Most commonly, the Markov switching models are estimated by the maximum likelihood method. For instance, Hamilton (1990) reports that by using the EM algorithm (Dempster et al., 1977), one can obtain maximum likelihood estimates that are relatively robust with respect to parameters' starting values. However, it is very difficult to obtain reasonable maximum likelihood estimates if a model contains too many parameters. For instance, a five-variable absorbing three-state MSVAR model with five lags has more than 400 parameters. Unfortunately, we often encounter this type of difficulty when we try to maximize the log-likelihood in such a huge model.

One way to circumvent this difficulty is to employ the Bayesian Markov chain Monte Carlo (MCMC) approach, as is used in this paper. The Bayesian method calculates the posterior distribution of parameters from the prior distribution and the observed data, then use it for statistical inferences. Even when the analytical calculation of the posterior distribution is formidable, the MCMC methods can provide feasible algorithms for sampling from the posterior distribution by constructing a Markov chain that has the desired posterior distribution as its stationary distribution. The state of the chain obtained after a large number of steps is then used as a sample from the desired posterior distribution, in order to make statistical inferences.

Among many MCMC methods, we adopt the Gibbs sampler in this paper. To demonstrate, we briefly explain the Gibbs-sampling procedure for a non-absorbing two-state MSVAR model. For details of the algorithm as well as an extension for a three-state case, see Chib $(1996,1998)$ or Kim and Nelson (1999).

Let $\theta, T$, and $\mathbf{y}_{t}$ denote the set of unknown parameters, the number of observations, and the observation at time $t$, respectively. To conduct the Gibbs sampler we divide $\theta$ into several, or four blocks in this MSVAR case, i.e., the set of the latent state variables $\left(\theta_{1}\right)$, the set of the transition probabilities $\left(\theta_{2}\right)$, the set of the covariance matrices $\left(\theta_{3}\right)$, and the set of the VAR coefficients $\left(\theta_{4}\right) .{ }^{12}$ Thus, it can be written $\theta=\left[\theta_{1}^{\prime}, \theta_{2}^{\prime}, \theta_{3}^{\prime}, \theta_{4}^{\prime}\right]^{\prime}$ with each of $\theta_{i}(i=1,2,3,4)$ are defined as: $\theta_{1}=\left[s_{1}, s_{2}, \ldots, s_{T}\right]^{\prime}, \theta_{2}=\left[p_{11}, p_{22}\right]^{\prime}, \theta_{3}=$ $\left[\operatorname{vech}(\boldsymbol{\Omega}(1))^{\prime}, \operatorname{vech}(\boldsymbol{\Omega}(2))^{\prime}\right]^{\prime}$, and $\boldsymbol{\theta}_{4}=\left[\boldsymbol{\beta}(1)^{\prime}, \boldsymbol{\beta}(2)^{\prime}\right]^{\prime}$, where $\boldsymbol{\beta}(j)$ is a column vector of the form $\boldsymbol{\beta}(j)=\left[\operatorname{vec}\left(\boldsymbol{\Phi}_{1}(j)\right)^{\prime}, \ldots, \operatorname{vec}\left(\boldsymbol{\Phi}_{p}(j)\right)^{\prime}\right]^{\prime}$. Further, let $\tilde{\mathbf{y}}_{t}=\left\{\mathbf{y}_{-p+1}, \mathbf{y}_{-p+2}, \ldots, \mathbf{y}_{t}\right\}$ and $p\left(\boldsymbol{\theta} \mid \tilde{\mathbf{y}}_{T}\right)$ be the desired posterior distribution. Then the Gibbs sampler allows us to generate random samples following $p\left(\theta \mid \tilde{\mathbf{y}}_{T}\right)$ as follows:

\section{Set initial values $\boldsymbol{\theta}^{(0)}$ and set $j=0$;}

12 Strictly speaking, $\left\{s_{t}\right\}_{t=1}^{T}$ are the latent state variables, not the parameters. However, since they are estimated from the data, they are usually treated as unknown parameters in the Bayesian framework. 
2. Draw $\boldsymbol{\theta}_{1}^{(j+1)}$ from $p\left(\boldsymbol{\theta}_{1} \mid \boldsymbol{\theta}_{2}^{(j)}, \boldsymbol{\theta}_{3}^{(j)}, \boldsymbol{\theta}_{4}^{(j)}, \tilde{\mathbf{y}}_{T}\right)$;

3. Draw $\boldsymbol{\theta}_{2}^{(j+1)}$ from $p\left(\boldsymbol{\theta}_{2} \mid \boldsymbol{\theta}_{1}^{(j+1)}, \boldsymbol{\theta}_{3}^{(j)}, \boldsymbol{\theta}_{4}^{(j)}, \tilde{\mathbf{y}}_{T}\right)$;

4. Draw $\boldsymbol{\theta}_{3}^{(j+1)}$ from $p\left(\boldsymbol{\theta}_{3} \mid \boldsymbol{\theta}_{1}^{(j+1)}, \boldsymbol{\theta}_{2}^{(j+1)}, \boldsymbol{\theta}_{4}^{(j)}, \tilde{\mathbf{y}}_{T}\right)$;

5. Lastly draw $\boldsymbol{\theta}_{4}^{(j+1)}$ from $p\left(\boldsymbol{\theta}_{4} \mid \boldsymbol{\theta}_{1}^{(j+1)}, \boldsymbol{\theta}_{2}^{(j+1)}, \boldsymbol{\theta}_{3}^{(j+1)}, \tilde{\mathbf{y}}_{T}\right)$;

6. Set $\boldsymbol{\theta}^{(j+1)}=\left[\left(\boldsymbol{\theta}_{1}^{(j+1)}\right)^{\prime},\left(\boldsymbol{\theta}_{2}^{(j+1)}\right)^{\prime},\left(\boldsymbol{\theta}_{3}^{(j+1)}\right)^{\prime},\left(\boldsymbol{\theta}_{4}^{(j+1)}\right)^{\prime}\right]^{\prime}$;

7. If $j+1=N$, stop the algorithm. Otherwise, repeat the algorithm from step 2 .

Here $N$ is the number of iteration and the first $N_{0}$ samples are discarded. Thus, $\left\{\boldsymbol{\theta}^{(j)}\right\}_{j=N_{0}+1}^{N}$ are considered as the samples following $p\left(\boldsymbol{\theta} \mid \tilde{\mathbf{y}}_{T}\right)$ approximately. ${ }^{13}$

As for the prior distributions of the unknown parameters, we basically assume the conjugate diffuse priors. However, in order to obtain the reliable estimation results, we make several adjustments. In step 2, we draw $\left\{s_{t}\right\}_{t=1}^{T}$ conditional on $\boldsymbol{\theta}_{2}^{(j)}, \boldsymbol{\theta}_{3}^{(j)}, \boldsymbol{\theta}_{4}^{(j)}$, and $\tilde{\mathbf{y}}_{T}$. If the number of observations that are classified in a regime is small, this makes it difficult to conduct the random sampling in steps 4 and 5. For instance, in step 5, we need to estimate VAR coefficients using the data classified as belonging to state $i$, which will clearly be difficult if the number of observations in a particular state is too small. In this paper, we assume that each state has at least 60 months, or 5 years of observations. This assumption is needed in order to both obtain the reliable estimation results and fulfill one of the purposes of this paper; namely, to detect the presence of relatively long-lived, not short-lived unusual, states. Hence, for a generated series of $\left\{s_{t}\right\}_{t=1}^{T}$, if the number of observations in a regime is less than 60 , then we discard the sample and draw another sample. In addition to this adjustment, we assume independent uniform distributions between $2 / 3$ and 1 for the priors of the transition probabilities, $p_{11}$ and $p_{22}$. Though this imposes a restriction that the expected duration of a regime to be at least three months, this is not a particularly strong assumption to detect long-lived states. ${ }^{14}$ For steps 4 and 5 we use simply the Normal-Wishart diffuse priors. ${ }^{15}$ The only difference between our model and the usual VAR model is that, to generate parameters for state $i$, we only use the data classified as belonging to state $i$ in step 2 .

\section{Empirical results}

\subsection{Data and common issues of VAR specification}

Our VAR model contains five variables. The sample period is from January 1975 to December $2002 .{ }^{16}$ To examine a possible structural change and its effect on monetary policy, we use the

\footnotetext{
13 In this paper, we set $N=30,000$ and $N_{0}=20,000$. No strong evidence of lack of convergence was found, based on the convergence diagnostic test proposed by Geweke (1992).

14 The expected duration of regime $i$ is $1 /\left(1-p_{i i}\right)$. See Kim and Nelson (1999, p. 72).

15 See Kadiyala and Karlsson (1997) for the Normal-Wishart diffuse priors for the VAR model.

16 Note that most of interest rate data are zeros after October 2002, which invalidates the normality assumption, hence our MSVAR analysis. To analyze the asymmetric effect created by the zero lower bound in the interest rate, the interest rate equation in VAR may be modeled as a Tobit-type specification. Although this is surely an interesting topic to pursue, it is beyond the scope of the paper, which focuses on the detection of a structural break in the Japanese economy over the last three decades. We, therefore, choose the end of 2002 as the endpoint for our sample. However, also note that our main results including that the non-absorbing two-state MSVAR model is the best model and interest rate monetary policy effect has significantly diminished after 1996 remain true, even if we extend our sample up to April 2005.
} 
same four monthly data as Miyao (2000). Real output $y$ is measured by seasonally adjusted industrial production, the nominal short-term interest rate $r$ by the collateralized overnight call rate (interbank interest rate), nominal money supply $m$ by the seasonally adjusted monetary base, and the exchange rate $e$ by the nominal effective exchange rate. ${ }^{17}$ In addition to these four variables, we include the consumer price index $p$ as the fifth variable. By including $p$, we aim to capture the effects of severe deflation in the 1990s. All variables are expressed in natural logarithms except for the call rate, and are multiplied by 100.

For the identification of monetary policy shocks, we use strategy proposed by Christiano et al. (1999). Specifically, we estimate a five-variable, block recursive VAR model, in which variables are stacked in the order of $y-p-r-m-e$ (hereafter, we refer to this system as the yprme model). We treat $y$ and $p$ as non-financial variables, $r$ and $m$ as policy instruments, and $e$ as a financial variable. In addition to the standard Christiano et al. (1999) assumptions stated in Section 2.1, we assume that $r$ is predetermined for $m$, in order to identify monetary policy shocks based on Keating (1996).

Prior to estimation, we take a first-difference of all variables. Thus our VAR model consists of $\left(\Delta y_{t}, \Delta p_{t}, \Delta r_{t}, \Delta m_{t}, \Delta e_{t}\right)$. This model, namely a VAR in differences model, does not allow five variables to be cointegrated. Sims et al. (1990), on the other hand, recommend working with the VAR in levels model. We chose the specification of differences for two reasons. First is the fact that all the variables we use are non-stationary, and are not cointegrated. ${ }^{18}$ Therefore, the VAR in differences is actually the correct specification. The second reason is to improve the small sample properties of the estimates. Although the sample size is relatively small, one of our models presumes three states. This means that the number of observations in each state is very limited. With such a small sample, using differences often improves the finite sample properties of the estimates. For these reasons, we estimate VAR using differences.

Finally, we chose the lag length to be five, and to be fixed in all cases. Since the average number of observations in each state using the absorbing three-state model is about 110 , we consider that a value of five is the longest lag length we can estimate in all the models with some constant degree of accuracy.

\subsection{Model comparison}

In this section, we compare estimation results of four structural VAR models: a model with no structural break (Model 1), a model with one permanent structural change (Model 2), a model with two permanent structural changes (Model 3), and a model with two non-absorbing states (Model 4).

To choose the best model, we employ the Akaike Information Criterion (AIC), which is a standard model selection criterion for the MLE framework, for two reasons. First, the marginal likelihood or the Bayes factor which is a typical measure for the Bayesian model selection is not well defined, since we basically use the conjugate diffuse priors for the Gibbs sampler. Second, Koop (2003, p. 258) notes that the AIC can often provide an effective way in Bayesian model se-

\footnotetext{
17 The full description of data can be found in Appendix A.

18 The results of our preliminary investigation on the unit root and cointegration analysis are similar with the findings of Miyao (2000). For unit root tests, we calculated conventional statistics such as ADF, DF-GLS (Elliott et al., 1996), PP (Phillips and Perron, 1988), and KPSS (Kwiatkowski et al., 1992), as well as a test proposed by Zivot and Andrews (1992) that assumes a possibility of structural break. In the interest of brevity, we do not reproduce these test results here. Detailed test results are available from the authors upon request.
} 
lection, even though it is hard to justify rigorously the use of AIC from the Bayesian perspective. For these reasons we will choose our best model using the AIC.

The values of AIC evaluated at the posterior means for Models 1 to 4 are 4190.25, 3981.79, 3982.97, and 3863.36, respectively. (Recall that we fixed the number of VAR lag length to be five for all specifications.) Through comparing these AICs, we address questions (i) through (iii) listed in Section 1.

In question (i), we asked "Was there a structural break in the Japanese economic system in the post-1975 period?" A comparison of the conventional VAR model (Model 1) and other models gives a clear answer. According to the AIC, models with at least one structural change uniformly provide a much better fit over Model 1. It is, therefore, reasonable to conclude that there was at least one structural break in the sample period.

Given the confirmation of structural breaks above, we consider the optimal number of structural breaks. Comparing the results of two-state models (Models 2 and 4) and three-state model (Model 3), it is evident that two-state models are preferable, meaning that investigation of more than two break points is not necessary.

Lastly, we examine the nature of state evolution, given that there are two states in the post1975 period through comparing two Models 2 and 4. Even though Model 4 includes just one additional parameter than Model 2, the reduction of AIC is substantial, indicating that Model 4 is the best model to describe dynamics of the Japanese monetary policy instruments as well as private sector behavior in the sample period.

In sum, our analysis shows that there were two states for the Japanese economic dynamics including monetary policy systems in the post-1975 period. In addition, the state evolution between these two states should be modeled as a transitory change. Thus, the Japanese economy has experienced not a permanent structural change, but several reversible state changes, which can be modeled by a non-absorbing two-state Markov switching model.

Our analysis so far considers the dynamics of the entire Japanese economic system described by five variables $y, p, r, m$, and $e$, through which we have found a clear evidence of state changes in the post-1975 period. This finding, however, does not necessarily imply that the effectiveness of the Japanese monetary policy has been experienced significant state changes. We will, therefore, examine the difference between the effects of monetary policy across two states by studying the impulse response functions to the monetary policy shocks in the next subsection. By doing so, answers to the fourth question listed in Section 1 can be deduced.

\subsection{Re-evaluation of monetary policy}

In the previous subsection, the non-absorbing two-state MSVAR is selected as a model representing the dynamics of monetary policy instruments, as well as private sector behavior, in the post-1975 period. This implies that each date is classified into either of the two states where the BoJ maybe use different policy instruments, resulting in very different effects. Let us take a closer look at these issues.

First, let us investigate the distribution of states by examining the pattern of smoothed probabilities. Fig. 1 depicts the smoothed probabilities of State 2 generated from Model 4 . Notice that the probability of State 2 has suddenly increased in January 1996. As noted earlier, Miyao (2000) has also detected a shift in VAR coefficients between 1995 and 1996 by grid searching for the break point. This timing almost coincides with the period that the Japanese economy has 


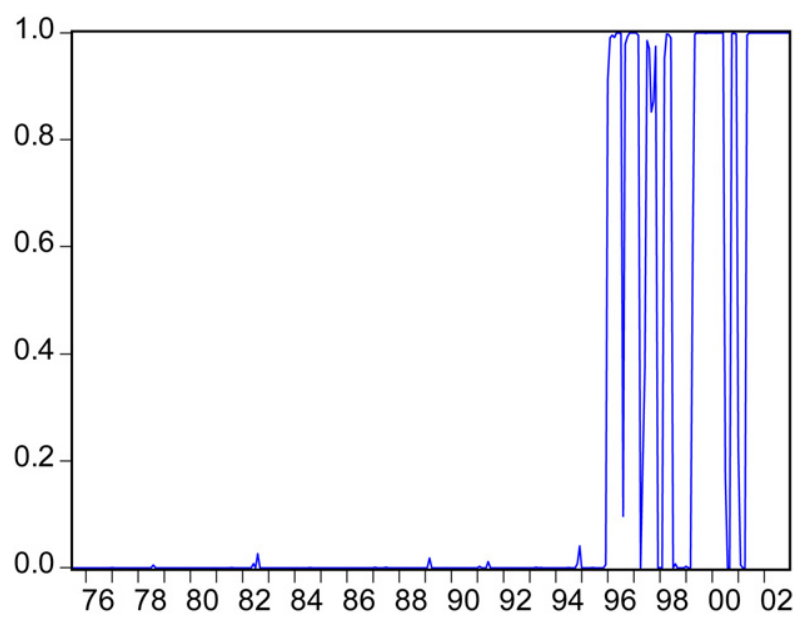

Fig. 1. Smoothed probability of State 2 .

fallen into the liquidity trap. ${ }^{19}$ Hence, it is very reasonable to conclude that the major change in the Japanese economy has emerged at around 1996.

However, this does not imply that the state of economy has completely changed since then. Recall that our specification treats the structural break not as a permanent event, but as a reversible phenomenon. Indeed, there are six occasions classified as State 1 even in the post-1996 period. ${ }^{20}$ We will address this issue in a later part of this section.

Given the classification of states, we investigate the responses of various economic aggregates to monetary policy shocks in each state. In what follows, we report the results of the call rate shock, followed by the results of monetary base shock.

Fig. 2 displays the impulse responses (solid line) of all the variables used in the VAR model to a contractionary interest rate innovation for each state, along with one standard deviation error bands (broken lines). ${ }^{21}$ The size of the shock is one standard deviation. Responses are plotted for a 60-month period. The left column in Fig. 2 is the responses in State 1, or the dominant state before December 1995. First, the response of $y$ to positive innovations in $r$ is persistently negative, implying that an unexpected tightening in interest rate policy surely reduces the level of real output. ${ }^{22}$ Second, an interpretation of the policy effects on the price level requires some caution since the effects are different depending on the time horizon. Initially, the response of price to a contractionary policy shock is inflation. However, this phenomenon ends within six

19 Krugman (1998, p. 167) notes that "Japanese money-market rates have been below 1 percent since 1995. It is true that Japan has not pushed money market rates down to their absolute minimum - there were still, at the time of writing, 43 basis points to go-but the economy is clearly in a very good approximation to liquidity-trap conditions."

20 They are: (1) August 1996; (2) April 1997 to June 1997; (3) December 1997 to February 1998; (4) July 1998 to March 1999; (5) July 2000 to September 2000; and (6) January 2001 to April 2001.

21 In econometrics, it is conventional to use two-standard deviation confidence bands. However, the use of two-standard deviation tends to generate very wide confidence intervals. This is a generic problem of the VAR specification because it includes a lot of parameters. Therefore, the impulse response is often evaluated with the use of one-standard deviation confidence intervals. For instance, see Christiano et al. (1996), Miyao (2000, 2002), and Shioji (2000).

22 In general, an interest rate innovation would have only a transitory effect on output. The reason why the interest rate shock shows a permanent long-run effect on output in Fig. 2 is due to the first-differenced specification. See Miyao $(2000,2002)$ for similar results. 

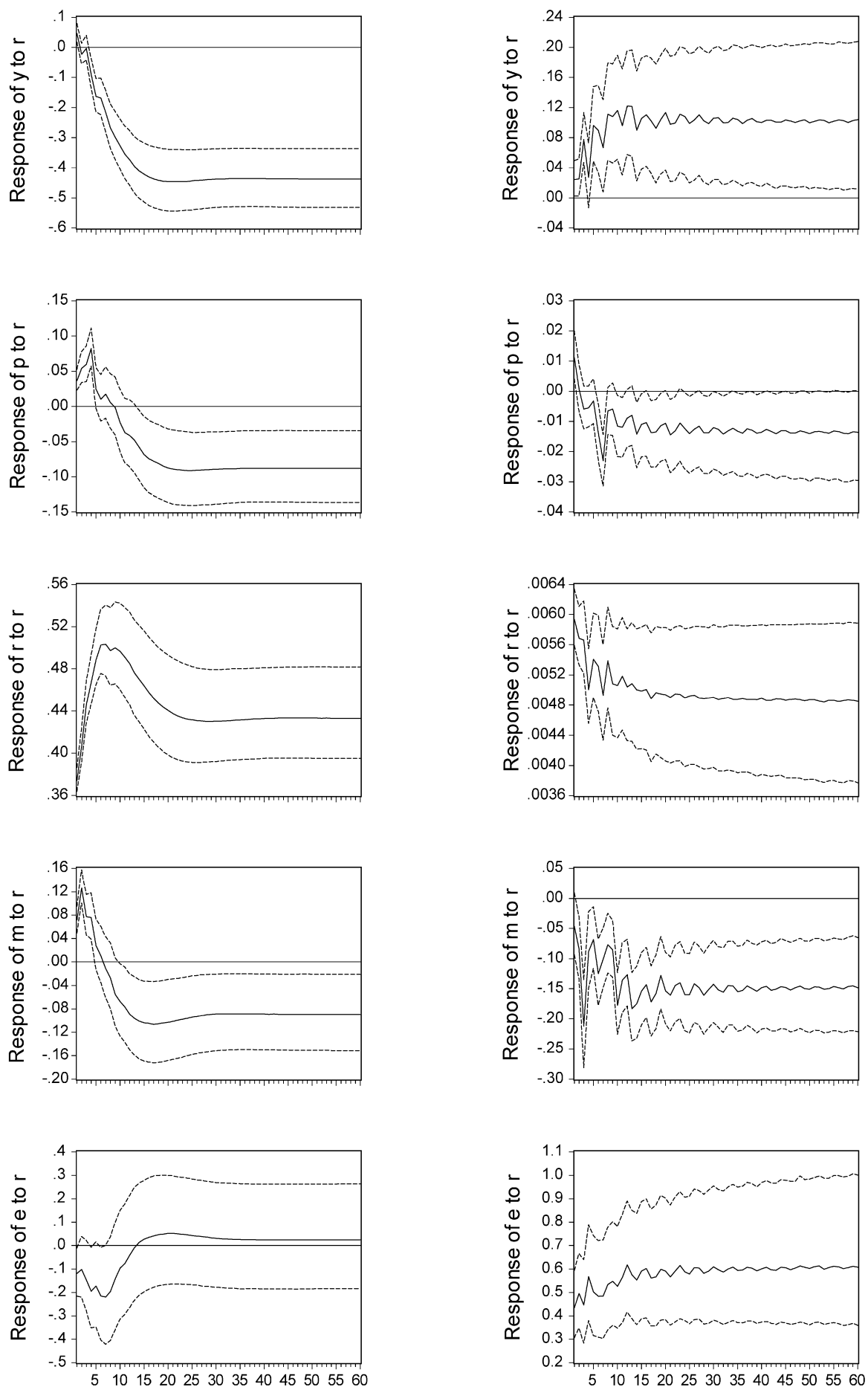

Fig. 2. Responses to a positive interest rate shock. 
months. Afterwards, a persistent negative response becomes evident. ${ }^{23}$ Therefore, we conclude that the responses of both output and price to interest rate shocks are consistent with the pattern predicted by standard economic theory. Likewise, a long-run response of monetary base to an interest rate innovation is negative, as theory predicts. Though it has a wide error band, the average response of exchange rate is also interpretable, i.e., a rise in $r$ eventually increases $e$. Therefore, the interest rate policy seems to work properly in State 1.

On the other hand, as can be seen from the right column in Fig. 2, the effectiveness of interest rate shocks has greatly diminished, or even reversed, in State 2. The top panel indicates that an expansionary (or negative) interest rate shock has a slight but significantly negative long-run effect on output, which contradicts with the theoretical prediction. Obviously, this should not be interpreted as that, a contractionary interest rate shock has a positive effect on output. Rather, we believe that this positive impulse responses of $y$ to $r$ is spurious, reflecting the economic confusion in the liquidity trap. As for the prices, a contractionary interest rate shock seems to generate the deflationary pressure instantaneously, though its effect is limited. These responses imply that the interest rate manipulation is not an effective policy option in State 2. As the period classified as State 2 almost coincides with the period that Japanese economy has fallen into the liquidity trap, the findings are reasonable. ${ }^{24}$

Does the result imply that the BoJ lost its policy instrument to stimulate the Japanese economy in State 2? It is now worth verifying the effect of the "innovations in the monetary base" as another indicator of monetary policy shock. Fig. 3 depicts the responses of each variable in the VAR to the monetary base innovations for each state.

Before examining these responses in detail, let us check if the policy shocks are correctly identified. If it is correctly identified, monetary base innovations should lower the level of interest rate. Third row of Fig. 3 depicts the response in each state. Results are clear-cut. Responses of $r$ to $m$ are positive in State 1 and negative in State 2. Therefore, the estimated monetary base innovations in State 2 are identified as monetary policy shocks whereas the innovations in State 1 should be interpreted as money demand shocks.

The right column of Fig. 3 depicts the effect of monetary base innovations in State 2. The responses of output to monetary base innovations is persistently positive, suggesting that the monetary base shock indeed has stimulating effects in the period of liquidity trap. Since the BoJ has announced and clearly explained its purpose and intention for the quantitative easing policy conducted in 2001 and after, our result indicates that it has an immediate impact on $y$. Interestingly, positive monetary innovations have almost no effect on price. This result is in consensus with the fact that the BoJ's ultra-loose monetary policy in the late 1990s gave no immediate inflationary effect to the economy.

Results can be summarized as follows. First, the suspicion that a structural break has emerged in the post-1975 period is confirmed. Second, the timing of a major break is most likely to be in

\footnotetext{
23 The strong positive responses of price to interest rate innovations are called a price puzzle (see Sims, 1992 and Christiano et al., 1999). To moderate this puzzle, Sims (1992) suggests the addition of commodity prices and exchange rate to the system. However, given the complexity of our current model, we do not include commodity prices to our VAR. Even with this limitation, the initial inflationary period disappears quickly. Thus, we conclude that the issue of the price puzzle can be disregarded.

24 One concern associated with our estimation results is a subtle identification problem in State 2 , since the interest rates were almost constant in this state. However, this should not be a problem, since before 2002 there is at least a small fluctuation in the interest rates, even after the adoption of the so-called zero interest rate policy (ZIRP) in 1999. Indeed, the impulse response function of interest rates has some significant effect on output, even in State 2, suggesting there is enough fluctuation in interest rates for identification.
} 

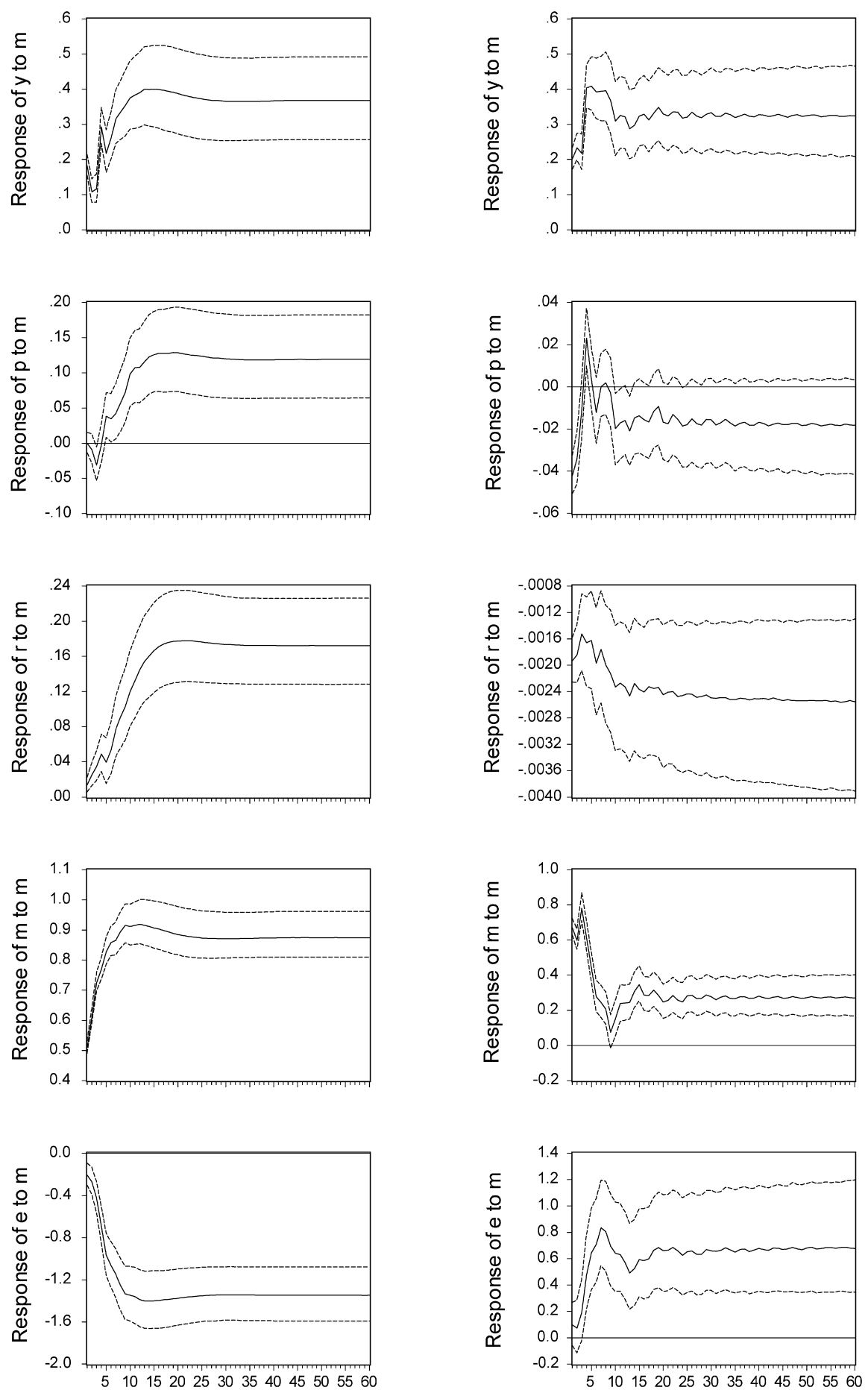

Fig. 3. Responses to a positive monetary base shock. 
1996, but the structural break is a reversible phenomena. Third, the interest rate monetary policy affects the economy in a conventional way in State 1, but its effect has significantly diminished in State 2. Lastly, monetary base works as a monetary policy indicator only in State 2. This is relevant, since the manipulation of monetary base becomes the only remaining option for the BoJ as interest rate approaches the zero lower bound. It seems that its shocks stimulate the economy although they are not strong enough to generate an inflationary pressure.

To conclude the empirical section, let us evaluate the Japanese monetary policy in the 1990s. After the bursting of the asset price bubble in the early 1990s, the BoJ has kept intermittently lowering the call rate, as the call rate has dropped by more than $5 \%$ in five years. A series of interest rate cuts were conducted prior to January 1996, i.e., State 1, so our results suggest that the BoJ's conventional policy was effective in stimulating the Japanese economy. However, after the interest rate approached the zero boundary in 1995 and it is believed that the economy was in the phase of liquidity trap, the effectiveness of interest rate shocks diminished. Most of the post-January 1996 period is classified as State 2, where the interest rate manipulation was not an effective monetary policy tool. This does not mean that the BoJ completely threw away the call rate manipulation from its policy instruments. Recall that there are six subperiods in the postJanuary 1996 period which are classified as State 1, indicating that the interest rate policy was still effective in those periods. More importantly, the last three occasions are related to the BoJ's policy shifts. ${ }^{25}$ In February 1999, the BoJ has started the ZIRP, and it has been lifted in August 2000. These episodes correspond to the fourth and fifth subperiods. The adoption of the second ZIRP associated with the quantitative easing policy in March 2001 is also identified as the sixth subperiod. These findings suggest two implications. First, State 2 should be interpreted not as a period when the interest rate policy is ineffective, but as a period that the interest rate manipulation is not actively used. Second, even in the post-1996 period, there are several occasions when the call rate manipulation was effective in stimulating the economy. The reverse is also true for the case when the BoJ lifted the ZIRP in August 2000. Our result indicates that the interest rate hike in August 2000 surely had some negative effects on output.

On the other hand, State 2 is a period where monetary base innovations are identified as policy shocks. As a matter of fact, the adoption of a new policy rule called "quantitative easing policy" in March 2001 has enhanced the importance of this policy shock. Under the new rule, the BoJ's policy target is officially shifted from the level of call rate to the BoJ checking account balance, which is a part of the monetary base. Initial target level (five trillion yen) has been revised several times in 2001, and it has reached 10 to 15 trillion yen in December 2001. As a result, the growth rate of monetary base in the March-April 2002 period, compared to the same time period in the previous year, is $30 \%$ or more. This shows the highest growth rate since the first oil crisis in 1974 (Bank of Japan, 2002). Thus, the estimated impulse responses of output to monetary base innovations imply that the BoJ has been stimulating the Japanese economy even in the period of liquidity trap.

\subsection{Checking the robustness of results}

The results reported so far are based on the five-variable block recursive VAR, in which the five variables are arranged in order of $y-p-r-m-e$. To check the robustness of the reported re-

25 Among the first three occasions, the second occasion coincides with the timing of consumption tax increase in April 1997, while the third occasion has started immediately after the emergence of large financial instability in November 1997. For a narrative history of the referred period, we see Ito and Mishkin (2004). 
sults, we additionally estimated four types of models, $y-r-m, r-y-m, y-r-m-e$, and $r-y-m-e$. They are different from the previous models in the ordering of variables and the exclusion of the CPI and exchange rate. Two of the models, $r-y-m$ and $r-y-m-e$, are previously estimated by Miyao (2000), and the rest of two models, $y-r-m$ and $y-r-m-e$, are the corresponding Christiano et al. (1999) identification based models. For these four combinations of the variables, we estimated the same four MSVAR models and compared them by the AIC. For all cases, the dominance of Model 4, that is, a non-absorbing two-state Markov switching model, is confirmed. Concerning the turning points in the smoothed probability, the timings of state changes suggested by these four models are quite similar to those found in the yprme model. Lastly, we examine the shapes of impulse response functions of various models closely. The results obtained from the all models are qualitatively similar to the results provided by the yprme model. All models indicate that interest rate manipulation was an effective tool in State 1, while monetary base innovations are identified as policy shocks only in State 2. Thus, our basic findings remain unaltered even if we change the orderings and the selection of variables.

\section{Conclusion}

The Japanese economy experienced a long-lasting economic stagnation in the 1990s. This paper focused on one of the hypotheses that explains this extraordinary phenomenon. Our goal was to verify if there exist any structural breaks in the effects of monetary policy in the lost decade by using a sophisticated econometric model.

In this paper, several block recursive structural VAR models were estimated to evaluate the policy shocks of the interest rate and the monetary base, under the emergence of severe deflation in the 1990s. Our VAR included the following five variables: output, consumer prices, interest rate, monetary base, and exchange rate. In order to consider the possibility that VAR parameters shift in the sample period, the law of state evolution was modeled by applying the Markov regime switching model.

Through comparison of competing specifications, we selected the non-absorbing two-state MSVAR model as the best model to describe the economic situation in the post-1975 period. The estimated results are summarized as the following. First, a possibility of structural break in the post-1975 period is confirmed. Second, the timing of a major break is most likely in 1996, but the structural break is a reversible phenomenon. For convenience, we call a state which is dominant before December 1995 as State 1 and another state which prevails after January 1996 as State 2. Third, the interest rate monetary policy affects the economy in a conventional way in State 1, but its effect has significantly diminished in State 2. Lastly, monetary base works as a monetary policy indicator only in State 2. In addition, it seems that its shocks stimulate the economy although they are not strong enough to generate an inflationary pressure.

Based on the results, we re-evaluated the BoJ's monetary policy in the 1990s as the following. During the first half of the decade, which starts with the collapse of the asset price bubble, the BoJ has kept propping out the Japanese economy through a series of interest rate cuts. Since these cuts were conducted prior to January 1996 (which is classified as State 1), our estimation result implies that the BoJ's policy was effective in propping up the Japanese economy. Even after the interest rate approaches the zero boundary and that the interest rate manipulation has become an ineffective policy instrument, the BoJ has kept stimulating the economy through expanding the monetary base. This corresponds to the period in State 2, during which the monetary base innovations are identified as monetary policy shocks. Although State 2 becomes the dominant state in the post- 1996 period, it is important to recall the reversible nature of our state classifica- 
tion. As our estimation has identified, there are several occasions in the post-1996 period which are classified as State 1. Thus, the BoJ's interest rate manipulation, such as an implementation or suspension of the ZIRP, surely had some effects on output even in the post-1996 period. In sum, the BoJ's policies in the second half of the decade were still effective in increasing output, although they are not strong enough to generate an inflationary pressure to escape from the trap of deflationary phase.

As a final contribution of this paper, we would like to mention one future research topic. In particular, studying the evaluation of both monetary and fiscal policy effects along with the possibility of structural breaks. For example, Bayoumi (2001) uses a standard VAR model to explain the slowdown in Japanese growth in the 1990s. Specifically, Bayoumi has investigated four possible explanations of the extended slump in the 1990s, two of which are the inadequacy and misconduct of monetary and fiscal policies. In reality, however, several authors have reported a decline in the estimated spending multiplier in the 1990s (see Kamoi and Tachibanaki, 2001; Kawade et al., 2004). Hence we believe that the type of examination we employed in this paper should be performed in order to properly evaluate these policy effects.

\section{Acknowledgments}

We are grateful to Ippei Fujiwara, Fumio Hayashi, Takeo Hoshi, Ryuzo Miyao, Etsuro Shioji, Yoshihiko Tsukuda, Toshiaki Watanabe, and seminar participants at the Tohoku University, Kobe University, Hitotsubashi University, Meisei University, and the Bank of Japan for helpful comments. We also thank an anonymous referee for many helpful suggestions. This research is partly financed by Seikei University Research Grant.

\section{Appendix A. Data}

The source and the description of the data used for the estimation are as follows. All the variables except for the monetary base are taken from International Financial Statistics (IFS) CD-ROM.

- $y_{t}$ : Industrial production, seasonally adjusted, taken from IFS (code: $15866 \ldots$ CZF...).

- $p_{t}$ : Consumer price index (all Japan, general, excluding imputed rent), taken from IFS, (code: $15864 \ldots$ ZF...).

- $r_{t}$ : Call rate (in \%), taken from IFS (code: 15860B...ZF...).

- $m_{t}$ : Monetary base (average outstanding, adjusted for the reserve requirement ratio changes, seasonally adjusted, 100 million yen), taken from the BoJ's web page (http://www.BoJ.or.jp/ type/stat/dlong/fin_stat/BoJ/cdab0150.csv). Note that the definition of monetary base is different before and after March 1981. Until March 1981, it is the sum of "banknotes in circulation," "coins in circulation," and "reserve deposit." However, from April 1981, it is revised as the sum of "banknotes in circulation," "coins in circulation," and "current account balances of the BoJ." The monetary base showed a sudden and temporal increase at around December 1999. Since this was a result of Y2K problem, we took a linear interpolation and eliminated this spike prior to the VAR analysis.

- $e_{t}$ : Nominal effective exchange rate, taken from IFS (code: 158... NEUZF...).

Except for the call rate, all the variables are transformed in logarithm and multiplied by 100 . 


\section{References}

Bank of Japan, 2002. Saikin no manetarī bēsu no zouka wo dou rikai suruka? (How should we understand the recent increase in monetary base?). Downloadable from http://www.BoJ.or.jp/type/ronbun/ron/research/data/ron0208b.pdf (in Japanese).

Bayoumi, T., 2001. The morning after: Explaining the slowdown in Japanese growth in the 1990s. J. Int. Econ. 53, 241-259.

Bernanke, B., Mihov, I., 1998. Measuring monetary policy. Quart. J. Econ. 113 (3), 869-902.

Blanchard, O.J., Quah, D., 1989. The dynamic effects of aggregate demand and supply disturbances. Amer. Econ. Rev. 79, 655-673.

Boschen, J., Mills L., 1991. The effects of countercyclical policy on money and interest rates: An evaluation of evidence from FOMC documents. Working paper No. 91-20, Federal Reserve Bank of Philadelphia.

Caballero, R., Hoshi T., Kashyap K., 2006. Zombie lending and depressed restructuring in Japan. Working paper No. 12129, NBER.

Chib, S., 1996. Calculating posterior distributions and model estimates in Markov mixture models. J. Econometrics 75, 79-98.

Chib, S., 1998. Estimation and comparison of multiple change point models. J. Econometrics 86, 221-241.

Christiano, L., Eichenbaum, M., Evans, C., 1996. Identification and the effects of monetary policy shocks. In: Blejer, M., Eckstein, Z., Hercowitz, Z., Leiderman, L. (Eds.), Financial Factors in Economic Stabilization and Growth. Cambridge Univ. Press, Cambridge, pp. 36-74.

Christiano, L., Eichenbaum, M., Evans, C., 1999. Monetary policy shocks: What have we learned and to what end? In: Taylor, J.B., Woodford, M. (Eds.), Handbook of Macroeconomics 1A. Elsevier, Amsterdam, pp. 65-148D.

Dempster, A., Laird, N., Rubin, D., 1977. Maximum likelihood from incomplete data via the EM algorithm. J. Roy. Statist. Soc. Ser. B 39 (1), 1-38.

Elliott, G., Rothenberg, T., Stock, J., 1996. Efficient tests for an autoregressive unit root. Econometrica 64 (4), 813-836.

Fujiwara, I., 2006. Evaluating monetary policy when nominal interest rates are almost zero. J. Japanese Int. Economies 20 (3), 434-453.

Gali, J., 1992. How well does the IS-LM model fit post-war US data? Quart. J. Econ. 92, 709-738.

Geweke, J., 1992. Evaluating the accuracy of sampling-based approaches to the calculation of posterior moments. In: Berger, J.O., Bernardo, J.M., Dawid, A.P., Smith, A.F.M. (Eds.), Bayesian Statistics, vol. 4. Clarendon Press, Oxford, pp. 641-649.

Hamilton, J., 1989. A new approach to the economic analysis of nonstationary time series and the business cycle. Econometrica 57 (2), 357-384.

Hamilton, J., 1990. Analysis of time series subject to changes in regime. J. Econometrics 45, 39-70.

Hayashi, F., 2000. Econometrics. Princeton Univ. Press.

Hayashi, F., Prescott, E., 2002. The 1990s in Japan: A lost decade. Rev. Econ. Dynam. 5, 206-235.

Ito, T., Mishkin F., 2004. Two decades of Japanese monetary policy and the deflation problem. Working paper No. 10878, NBER.

Kadiyala, K.R., Karlsson, S., 1997. Numerical methods for estimation and inference in Bayesian VAR-models. J. Appl. Econometrics 12 (2), 99-132.

Kamoi, K., Tachibanaki, T., 2001. Zaisei seisaku ga minkan juyo ni ataeta eikyo ni tsuite-Structural VAR ni yoru kensho (On the effect of fiscal policy to the private demand-Examination by structural VAR). Finan. Rev. 55, $165-185$ (in Japanese).

Kasa, K., Popper, H., 1997. Monetary policy in Japan: A structural VAR analysis. J. Japanese Int. Economies 11, 275295.

Kawade, M., Itoh, A., Nakazato, T., 2004. 1990-nen ikou no zaisei seisaku no kouka to sono henka (The effect of fiscal policy and its change in the post-1990). In: Ihori, T. (Ed.), Nihon no Zaisei Akaji (Japanese Fiscal Deficit). Iwanami Shoten, pp. 105-123 (in Japanese).

Keating, J., 1996. Structural information in recursive VAR orderings. J. Econ. Dynam. Control 20, 1557-1580.

Kim, C.-J., Nelson, C., 1999. State-Space Models with Regime Switching: Classical and Gibbs-Sampling Approaches with Applications. MIT Press.

Koop, G., 2003. Bayesian Econometrics. Wiley-Interscience.

Krugman, P., 1998. It's baaack! Japan's slump and the return of the liquidity trap. Brookings Pap. Econ. Act. 2, 137-205.

Kuttner, K., Posen, A., 2001. The great recession: Lessons for macroeconomic policy from Japan. Brookings Pap. Econ. Act. 2, 93-160.

Kuttner, K., Posen, A., 2002. Fiscal policy effectiveness in Japan. J. Japanese Int. Economies 16 (4), 536-558. 
Kwiatkowski, D., Phillips, P.C.B., Schmidt, P., Shin, Y., 1992. Testing the null hypothesis of stationary against the alternative of a unit root. J. Econometrics 54, 159-178.

Leeper, E., Sims, C., Zha, T., 1996. What does monetary policy do? Brookings Pap. Econ. Act. 2, 1-63.

McCallum, B., 2000. Theoretical analysis regarding a zero lower bound on nominal interest rates. J. Money, Credit, Banking 32 (4), 870-904.

Miyao, R., 2000. The role of monetary policy in Japan: A break in the 1990s? J. Japanese Int. Economies 14, $366-384$.

Miyao, R., 2002. The effects of monetary policy in Japan. J. Money, Credit, Banking 34 (2), 376-392.

Miyao, R., 2006. Nihon keizai no hendou youin: Seisansei shokku no yakuwari (The variation factors of Japanese economy: Role of productivity shocks). Working Paper Series No. 06-J-1, Bank of Japan (in Japanese).

Nakashima, K., 2006. The Bank of Japan's operating procedures and the identification of monetary policy shocks: A reexamination using the Bernanke-Mihov approach. J. Japanese Int. Economies 20 (3), 406-433.

Orphanides, A., Wieland, V., 2000. Efficient monetary policy design near price stability. J. Japanese Int. Economies 14 , $327-365$.

Phillips, P.C.B., Perron, P., 1988. Testing for a unit root in time series regression. Biometrika 75, 335-346.

Primiceri, E.G., 2005. Time varying structural vector autoregressions and monetary policy. Rev. Econ. Stud. 72, 821-852.

Romer, C., Romer, D., 1989. Does monetary policy matter? A new test in the spirit of Friedman and Schwartz. In: Blanchard, O., Fischer, S. (Eds.), NBER Macroeconomics Annual. MIT Press, Cambridge, pp. 121-170.

Shioji, E., 2000. Identifying monetary policy shocks in Japan. J. Japanese Int. Economies 14 (1), $22-42$.

Sims, C., 1980. Macroeconomics and reality. Econometrica 48, 1-48.

Sims, C., 1986. Are forecasting models usable for policy analysis? Fed. Res. Bank Minneapolis Quart. Rev. Winter, $2-16$.

Sims, C., 1992. Interpreting the macroeconomic time series facts: The effects of monetary policy. Europ. Econ. Rev. 36 (5), 975-1000.

Sims, C., Zha, T., 2006. Were there regime switches in US monetary policy? Amer. Econ. Rev. 96 (1), 54-81.

Sims, C., Stock, J., Watson, M., 1990. Inference in linear time series models with some unit roots. Econometrica 58, 113-144.

Zellner, A., 1962. An efficient method of estimating seemingly unrelated regressions and tests for aggregation bias. J. Amer. Statist. Assoc. 57, 348-368.

Zivot, E., Andrews, D., 1992. Further evidence on the great crash, the oil-price shock, and the unit-root hypothesis. J. Bus. Econ. Statist. 10 (3), 251-270. 